\title{
Lower respiratory tract infections: not only less antibiotic prescriptions but also more evidence, please
}

Management of both upper and lowerespiratory tract infection is very relevant in general practice, mainty because of the high incidence of these two conditions and their effects on daily activities and quality of life of patients. In this issue of the journal Feldman [1] reviews the available literature on the management of lower respiratory tract infection. To what extent does this evidence help us in daily practice?

Accurate diagnosis is sometimes difficult in primary care. Several authors have demonstrated that a considerable proportion of patients presenting with an acute cough have in fact undetected asthma or COPD [2,3]. Of those patients whose acute cough lasts longer than two weeks, up to $50 \%$ are said to have a chronic obstructive lung disease; patient characteristics such as age, pack-years of smoking, symptoms of wheezing and allergic complaints should assist the clinician. However, these findings have not yet been confirmed by others. Furthermore, combinations of signs, symptoms and simple additional tests were not assessed by these authors. Another important diagnostic problem is that of differentiating between acute bronchitis and pneumonia. Several authors have pointed out how difficult it is to diagnose pneumonia on the basis of signs and symptoms alone $[4,5]$. Some have shown that testing C-reactive protein (CRP) might provide added diagnostic value and support the general practitioner in detecting or ruling out pneumonia [6-8]. The diagnostic models from these elegant but small studies are yet to be validated in other populations but it does become more clear now that CRP has relevant diagnostic value in primary care.
Who might benefit from antibiotics? Feldman [1] correctly states that the average patient with acute bronchitis will not benefit from antimicrobial treatment; however, patients present in primary care with a wide variety of clinical pictures. Should we withhold antibiotics from young children or elderly patients who cough purulent sputum and have fever? The answer to this question is simply not known. As long as good studies in relevant subgroups of patients are lacking, any guideline in this field will be based partly on expert opinion rather than high grade evidence.

The other important issue for primary care physicians in managing these patients is implementation of evidence. While there are gaps in our knowledge, current guidelines and reviews like Feldman's provide substantial evidence-based advice that really should be implemented in daily practice. For example, healthy adults with an acute cough and no signs of pneumonia whatsoever should not be treated with an antibiotic; however, the majority of these patients do get this treatment in most European countries. Feldman rightfully emphasizes the importance of medical education, giving information to patients and shared decision making in this respect. Numerous studies, however, have pointed out that implementation of evidencebased medicine needs more than this [9]. Feedback of individual prescription rates, local engagement of GPs and pharmacists, academic detailing and public campaigns are also measures that should be considered essential if one is aiming at rational management of respiratory tract infections in primary care. 


\section{References}

[1] Feldman C. Appropriate management of lower respiratory tract infections in primary care. Primary Care Respiratory Journal 2004;13(3):159-66.

[2] Thiadens HA, de Bock GH, Dekker FW, Huysman JA, van Houwelingen JC, Springer MP, et al. Identifying asthma and chronic obstructive pulmonary disease in patients with persistent cough presenting to general practitioners: descriptive study. BMJ 1998;316(7140):1286-90.

[3] Van Schayck CP, Loozen JM, Wagena E, Akkermans RP, Wesseling GJ. Detecting patients at a high risk of developing chronic obstructive pulmonary disease in general practice: cross sectional case finding study. BMJ 2002;324(7350):1370.

[4] Metlay JP, Kapoor WN, Fine MJ. Does this patient have community-acquired pneumonia? Diagnosing pneumonia by history and physical examination. JAMA 1997;278(17): 1440-5.

[5] Margolis P, Gadomski A. The rational clinical examination. Does this infant have pneumonia? JAMA 1998;279(4):308-13.

[6] Melbye H, Straume B, Aasebo U, Brox J. The diagnosis of adult pneumonia in general practice. The diagnostic value of history, physical examination and some blood tests. Scand J Prim Health Care 1988;6(2):111-7.

[7] Hopstaken RM, Muris JW, Knottnerus JA, Kester AD, Rinkens $\mathrm{PE}$, Dinant GJ. Contributions of symptoms, signs, erythrocyte sedimentation rate, and C-reactive protein to a diagnosis of pneumonia in acute lower respiratory tract infection. $\mathrm{Br} \mathrm{J}$ Gen Pract 2003;53(490):358-64.

[8] Flanders SA, Stein J, Shochat G, Sellers K, Holland M, Maselli $\mathrm{J}$, et al. Performance of a bedside $\mathrm{C}$-reactive protein test in the diagnosis of community-acquired pneumonia in adults with acute cough. Am J Med 2004;116(8): 529-35.

[9] Grol R, Grimshaw J. From best evidence to best practice: effective implementation of change in patients' care. Lancet 2003;362(9391):1225-30.

T.J.M. Verheij

University Medical Center Utrecht Julius Centre for Health Sciences and Primary Care Heidelberglaan 100, 3584CX Utrecht Netherlands Tel.: +313025093 58; fax: +31302505480 E-mailaddress: t.j.m.verheij@med.uu.nl (T.J.M. Verheij)

27 June 2004

Available online at www.sciencedirect.com

science $\boldsymbol{d}$ Directo 